\title{
Research Concerning the Use of Polynomial Functions in the Study of the Conventional Sucker Rod Pumping Units
}

\author{
DORIN BADOIU* \\ Petroleum-Gas University of Ploiesti, 39 Bucuresti Blvd., 100680, Ploiesti, Romania
}

\begin{abstract}
The analysis of the conventional sucker rod pumping units and especially their dynamics is laborious and requires a large amount of calculations due to the constructive complexity of the component structural elements. Therefore, expressing in a simplified but sufficiently precise form the various cinematic and dynamic parameters that characterize the proper functioning of the pumping units is extremely useful in analyzing the possibilities of their functional optimization. In the paper are presented a series of results concerning the expressing of some cinematic and dynamic parameters using polynomial functions in the case of the mechanism of a C-640D-305-120 pumping unit. The simulations have been performed with a computer program developed by the author using Maple programming environment. Experimental records processing was performed with the program Total Well Management.
\end{abstract}

Keywords: sucker rod pumping unit, kinematics, dynamics, polynomial functions

The analysis of the sucker rod pumping installations in the perspective of their functional optimization requires an accurate determination of the parameters that characterize the operation of the pumping unit mechanism and those corresponding to the movement of the sucker rod column [1-3]. On the other hand, especially the analysis of their dynamics is extremely laborious and requires a large amount of calculations due to the constructive complexity of the component structural elements of the pumping unit mechanism and due to the complex loads that appear during the movement of the sucker rod column [4-8]. Therefore, expressing in a simplified but sufficiently precise form the various cinematic and dynamic parameters that characterize the proper functioning of the sucker rod pumping installations is extremely useful in analyzing the possibilities of their functional optimization.

In this paper are presented some results concerning the use of the polynomial functions for expressing some cinematic and dynamic parameters corresponding to the operation of the mechanism of a C-640D-305-120 pumping unit. Some significant results concerning the cinematic and dynamic analysis of the mechanisms that have strongly helped to the achievement of the research from this paper are presented in [9-14]. The simulations have been performed with a computer program developed by the author using Maple programming environment [15] and the experimental records processing was performed with the program Total Well Management [16].

\section{Experimental part}

It has been analyzed a well serviced by a C-640D-305120 pumping unit manufactured by Lufkin [17]. The experimental records have been processed using the program Total Well Management [16]. In establishing the polynomial function corresponding to the variation on a cinematic cycle of the motor moment at the crankshaft of the analyzed pumping unit using the simulation program mentioned before was used the record concerning the variation of the force at the polished rod for the stroke 70 (fig. 1).

The simulation results have been compared with the experimental records obtained for the variation on a cinematic cycle of the motor moment at the crankshaft for the strokes 70, 80 and 85 (fig. 2-4).

Establishing the polynomial function corresponding to the variation of the motor moment at the crankshaft

The mechanism of a conventional pumping unit is presented in figure 5 . For establishing the variation on a cinematic cycle of the motor moment $\mathrm{M}_{\mathrm{m}}$ at the crankshaft

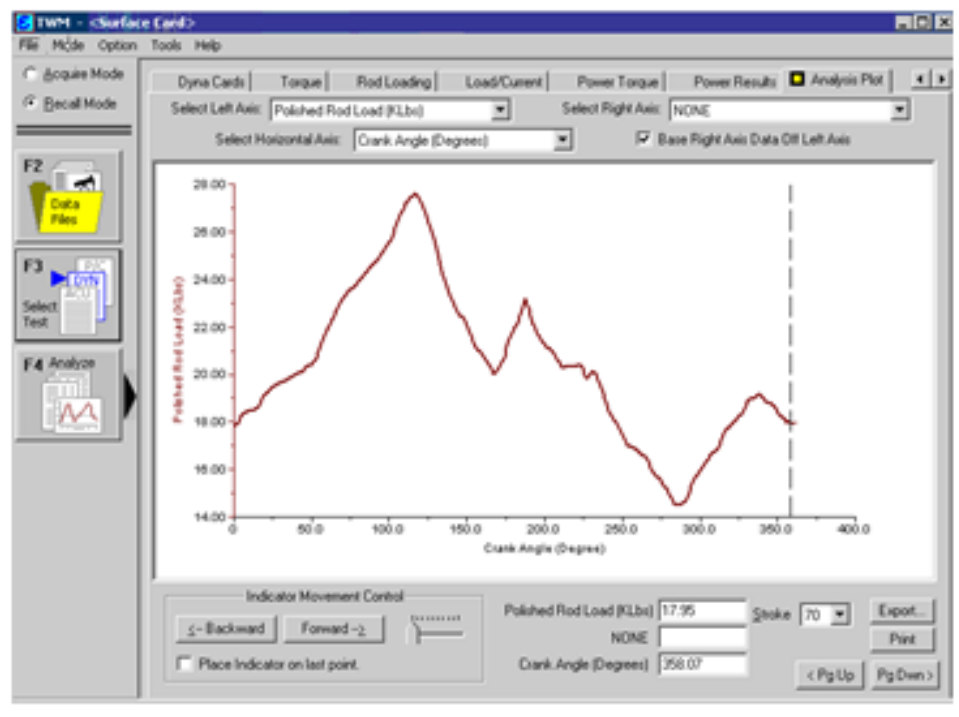

Fig. 1. The variation of the force at the polished rod during the stroke 70

* email: dorin.badoiu@gmail.com 


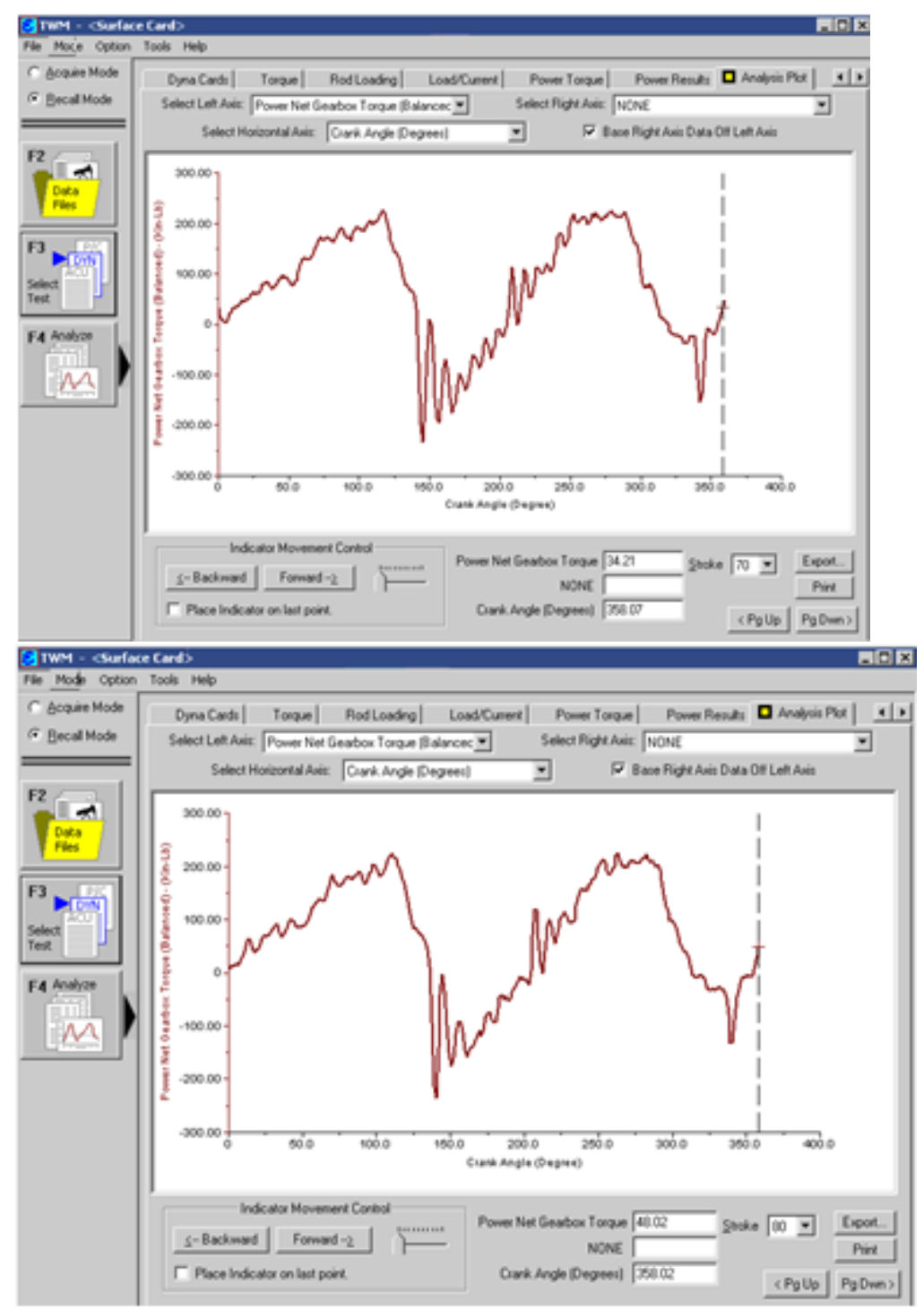

Fig. 2. The variation of the motor moment at the crankshaft during the stroke 70

Fig. 3. The variation of the motor moment at the crankshaft during the stroke 80

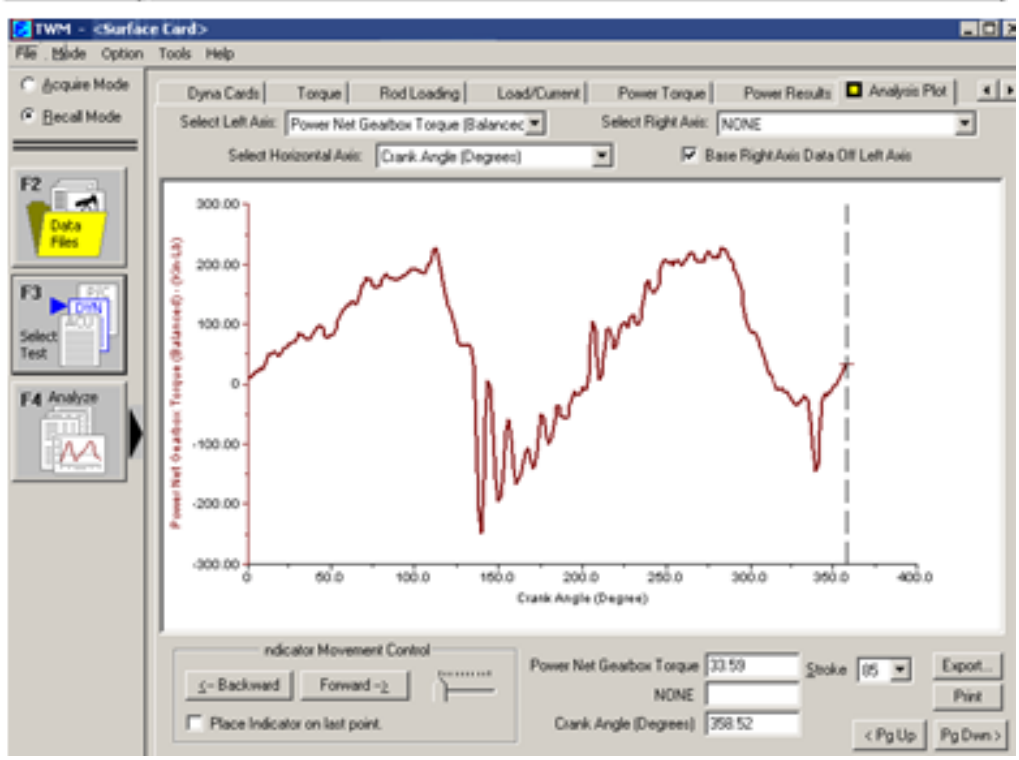

Fig. 4. The variation of the motor moment at the crankshaft during the stroke 85

are taken into account the weight $G_{1}$ of the cranks, the weight $G$ of the balancing counterweights and the force $F$ acting at the end of the polished rod. In fig.ure 5 with $C_{1}$ was noted the mass center of the cranks and $m_{1}$ represents the total mass of the balancing counterweights.

The motor moment $\mathrm{M}_{\mathrm{m}}$ at the crankshaft is calculated by expressing the dynamic equilibrium in instantaneous powers with the following relation:

$$
\bar{M}_{m} \cdot \bar{\omega}_{1}+\bar{G}_{1} \cdot \bar{v}_{C_{t}}+\bar{G}_{C G} \cdot \bar{v}_{A^{\prime}}+\bar{F} \cdot \bar{v}_{D}=0
$$

where: $\omega_{1}$ is the angular speed of the cranks; $\bar{v}_{C 1}=\bar{\omega}_{1} \mathrm{x}$ $\overline{O C}_{1}$ is the speed of the mass center $C_{1}$ of the cranks; $\bar{v}_{1}=\bar{\omega} \times \overline{O A}^{\prime}$ is the speed of the point where is acting the weight $G_{\text {of }}$ of the balancing counterweights; $\bar{v}_{\text {is }}$ is the speed of the end of the polished rod that can be established with the relation [6]: $v_{0}=\omega_{3^{\prime}} . C D$, where is the angular speed of the rocker that can be calculated with the following relation: 

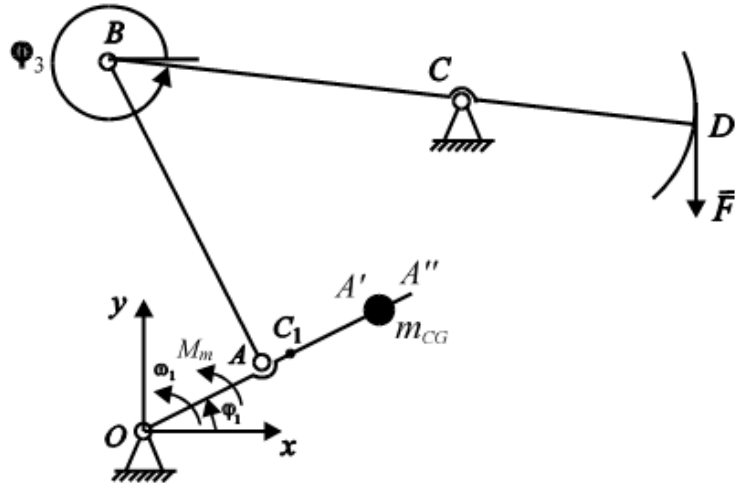

$\omega_{3}=\dot{\varphi}_{3}=\frac{\mathrm{d} \varphi_{3}}{\mathrm{~d} \varphi_{1}} \cdot \frac{\mathrm{d} \varphi_{1}}{\mathrm{~d} t}=\omega_{1} \cdot \frac{\mathrm{d} \varphi_{3}}{\mathrm{~d} \varphi_{1}}$
Fig. 5. The mechanism of a conventional pumping unit

The manner of determining the variation of the angle $\varphi_{3}$ according to the angle $\varphi_{1}$ (fig. 5) is presented in [6].

The variation on a cinematic cycle of the force $F$ at the end of the polished rod can be expressed according to the angle $\varphi_{1}$ with a polynomial function whose coefficients are calculated with the method of the least squares [18]:

$$
F\left(\varphi_{1}\right)=c_{0}+c_{1} \cdot \varphi_{1}+c_{2} \cdot \varphi_{1}^{2}+\ldots+c_{m} \cdot \varphi_{1}^{m}
$$

The values of the coefficients $c_{i}, i=\overline{0, m}$, that gives the best approximation of the variation on a cinematic cycle of the force $F$ can be determined by solving the following system of equations [18]:

$$
\left\{\begin{array}{l}
c_{0} \cdot(n+1)+c_{1} \cdot \sum_{i=0}^{n} \varphi_{1 i}+c_{2} \cdot \sum_{i=0}^{n} \varphi_{1 i}^{2}+\ldots+c_{m} \cdot \sum_{i=0}^{n} \varphi_{1 i}^{m}=\sum_{i=0}^{n} F\left(\varphi_{1 i}\right) \\
c_{0} \cdot \sum_{i=0}^{n} \varphi_{1 i}+c_{1} \cdot \sum_{i=0}^{n} \varphi_{1 i}^{2}+c_{2} \cdot \sum_{i=0}^{n} \varphi_{1 i}^{3}+\ldots+c_{m} \cdot \sum_{i=0}^{n} \varphi_{1 i}^{m+1}=\sum_{i=0}^{n} \varphi_{1 i} \cdot F\left(\varphi_{1 i}\right) \\
c_{0} \cdot \sum_{i=0}^{n} \varphi_{1 i}^{m}+c_{1} \cdot \sum_{i=0}^{n} \varphi_{1 i}^{m+1}+c_{2} \cdot \sum_{i=0}^{n} \varphi_{1 i}^{m+2}+\ldots+c_{m} \cdot \sum_{i=0}^{n} \varphi_{1 i}^{2 m}=\sum_{i=0}^{n} \varphi_{1 i}^{m} \cdot F\left(\varphi_{1 i}\right)
\end{array}\right.
$$

where $\varphi_{11}$ are the values of the angle $\varphi_{1}$ where have been recorded the values of the force at the polished rod.

In a similar way, $d \varphi_{3} / d \varphi_{1}$ that appears in the calculus relation of the angular speed $\omega_{3}$ and the trigonometric function $\cos \varphi_{1}$ that appears in the expressions of the terms $\bar{G}_{1} \cdot \bar{v}_{C 1}$ and $\bar{G}_{C G} \cdot \bar{v}_{A^{\prime}}$ in relation (1) can be expressed with polynomial functions, so that in the end is obtained the variation of the motor moment $\mathrm{M}_{\mathrm{m}}$ expressed in a polynomial form.

\section{Simulation results and discussions}

The analysis of the mechanism of the conventional sucker rod pumping units presented before has been transposed by the author into a computer program using Maple programming environment [15]. The simulations have been performed in the case of a C-640D-305-120 pumping unit produced by Lufkin [17], whose component elements have the following dimensions: $O A=30$ in. $(0.762 \mathrm{~m}) ; A B=133.5 \mathrm{in}$. (3.3909 m); $B C=111.09 \mathrm{in}$. $(2.8217 \mathrm{~m}) ; C D=155 \mathrm{in}$. (3.937 m). The coordinates of the point $C$ (fig. 5) are [17]: $x_{c}=111\left(2.8194 \mathrm{~m}\right.$ ) and $y_{c}=138$ in. ( $3.5052 \mathrm{~m}$ ). The value of the crank angle $\varphi_{14}$ corresponding to the beginning of the upward movement of the sucker rod column is $88.976^{\circ}[6]$.

The simulations have been accomplished by considering the following values of the other parameters involved in calculations: $O A^{\prime}=46$ in. $(1.1684 \mathrm{~m}) ; O A^{\prime \prime}=95 \mathrm{in} .(2.413 \mathrm{~m}) ; \mathrm{m}_{C G}=4808 \mathrm{~kg} ; q_{1}=722 \mathrm{~kg} / \mathrm{m}$, where $q_{1}$ is the linear mass of the cranks. The angular working speed of the cranks has been of $6.667 \mathrm{rot} / \mathrm{min}$.

In evaluating the polynomial function corresponding to the variation of the force at the polished rod for the stroke 70 (fig. 1) it has been consider $m=30$. In figure 6 are presented the values of the coefficients $c_{i}, i=0, m$, in the order in which they are found in the polynomial function.

\footnotetext{
[17.3620601881055553220321697966232,51.5964912849788330026829256211, -1602.864286037982358847948537062, 25835.74886451282985366607694462 . $.236662 .7885445389966207995684325,0.136660444775907293824141873394610^{7}, 0.033562239376659113268841860945310^{7}, 0.1503303946806410344281700165$ $-0.314264022817558212684873127493310^{8}, 0.50388499477306973280327619931610^{8},-0.63351487115188507266565868027010^{8}, 0.635109601493705541644317$ $-0.51413614507430077581170487171810^{8}, 0.339171292579536111640094905279110^{8},-0.183442241278090130055085601498410^{8}, 0.81583518556391368119304$ $-0.29818016846010592532151447452510^{7}, 890895.282163225089395427822321,-214802.139165159900897516670474,40633.8368025337149805066223209$. .5629.28553839732700279494951189, 443.94872894243937610408360397, 21.162031833770473556652669640, - .13 .8678941647474952445657357725 . $2.58615911128635237613753223017,-0.310313598522244108365948322808,0.0264053215660783522124532236532,-0.001601075416680539714930272834985$, $\left.0.0000663417702502561496888224305961,-0.169236183583102354115501219606010^{-5}, 0.201124561075871755225017332245810^{-7}\right]$
}

Fig. 6. The values of the coefficients of the polynomial function corresponding to the force at the polished rod 


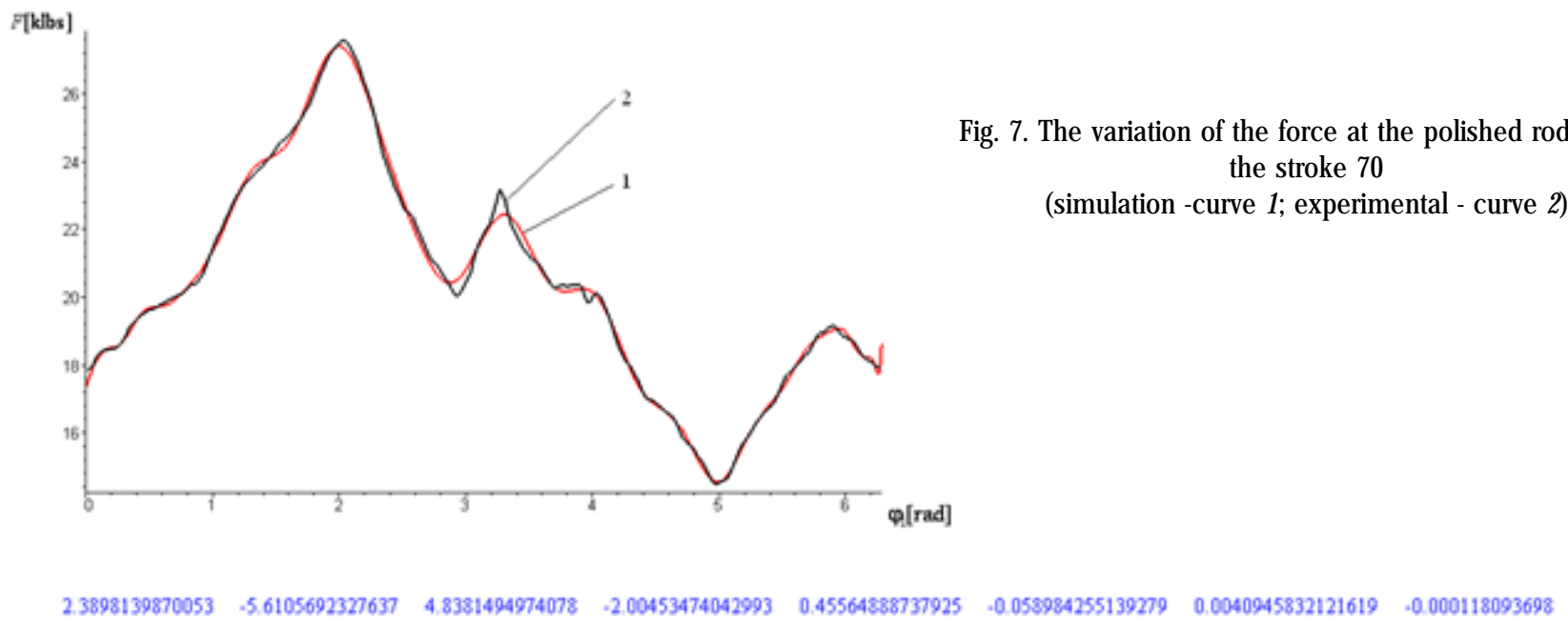

Fig. 8. The values of the coefficients of the polynomial function corresponding to $d \varphi_{3} / d \varphi_{1}$

$\omega[\mathrm{rad} / \mathrm{s}]$

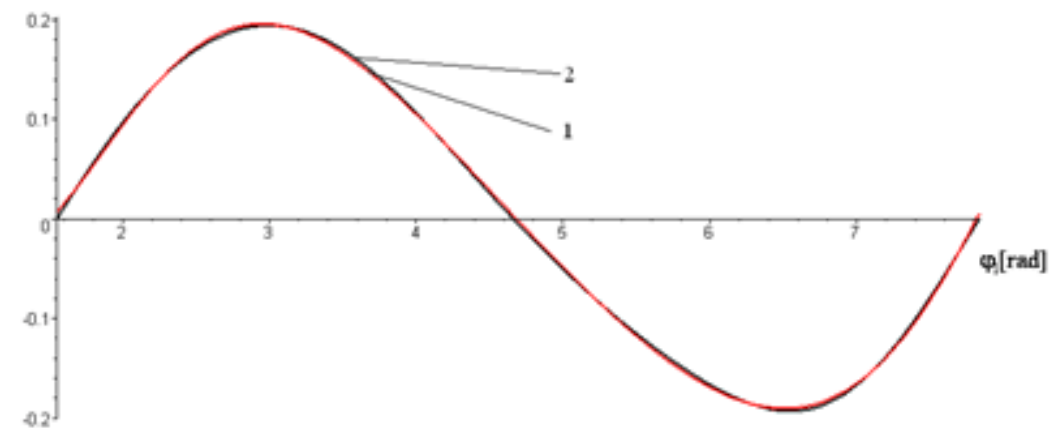

Fig. 9. The variation of the angular speed $\omega_{3}$ during a cinematic cycle using the polynomial function (curve 1) and the exact kinematics (curve 2)

In figure 7 the curve 1 represents the variation of the force at the polished rod during a cinematic cycle beginning with the upward movement of the sucker rod column obtained using the polynomial function and the curve 2 corresponds to the variation of its measured values.

In evaluating the polynomial function corresponding to the variation of $d \varphi_{3} / d \varphi_{1}$ during a cinematic cycle beginning with the crank angle $\varphi_{1 d}$ it has been consider $m=7$. In figure 8 are presented the values of the coefficients $\mathrm{c}_{\mathrm{i}}, \mathrm{i}=\overline{0, \mathrm{~m}}$, in the order in which they are found in this polynomial function.
In figure 9 the curve 1 represents the variation of the angular speed during a cinematic cycle beginning with the crank angle $\varphi_{1 d}$ obtained using the polynomial function corresponding to $\mathrm{d} \varphi_{3} / \mathrm{d} \varphi_{1}$ and the curve 2 corresponds to the variation of its values calculated with relation (2).

In figure 10 are presented the values of the coefficients $c_{i}, i=\overline{0, m}$, in the order in which they are found in the polynomial function that approximates during a cinematic cycle beginning with the crank angle $\varphi_{\text {dd }}$ the trigonometric function $\cos \varphi$, that appears in the expressions of the terms $\overline{\mathrm{G}}_{1} \bar{v}_{\mathrm{v}}$ and $\overline{\mathrm{G}}_{\mathrm{C} \cdot \bar{v}_{\mathrm{A}^{\prime}}}$ in relation (1). In this case it has been consider $m=6$.

\section{$\begin{array}{lllllll}-1.39415489974741 & 4.36477424361387 & -3.59346698547035 & 1.06195802915168 & -0.127007215422111 & 0.0051360810744934 & 0.000017387437409450\end{array}$}

Fig. 10. The values of the coefficients of the polynomial function corresponding to $\cos \varphi_{1}$

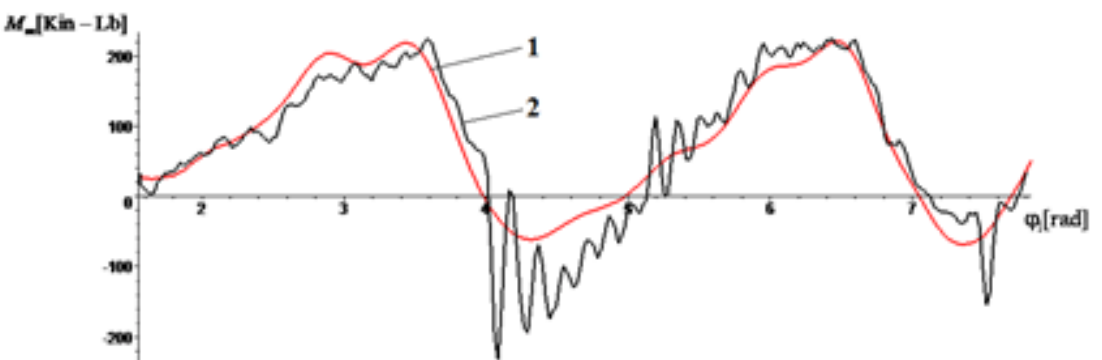

$M_{-}[\mathrm{Kin}-\mathrm{Lb}]$

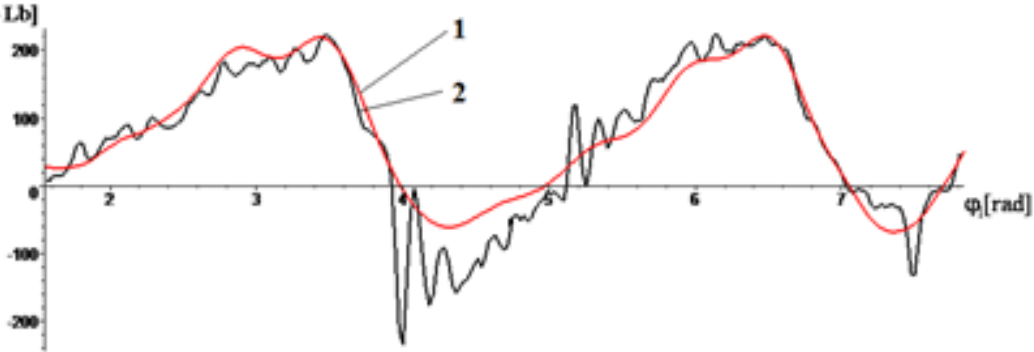

Fig. 11. The variation of the motor moment at the crankshaft during the stroke 70 (simulation -curve 1; experimental - curve 2)
Fig. 12. The variation of the motor moment at the crankshaft during the stroke 80 (simulation -curve 1 ; experimental - curve 2) 


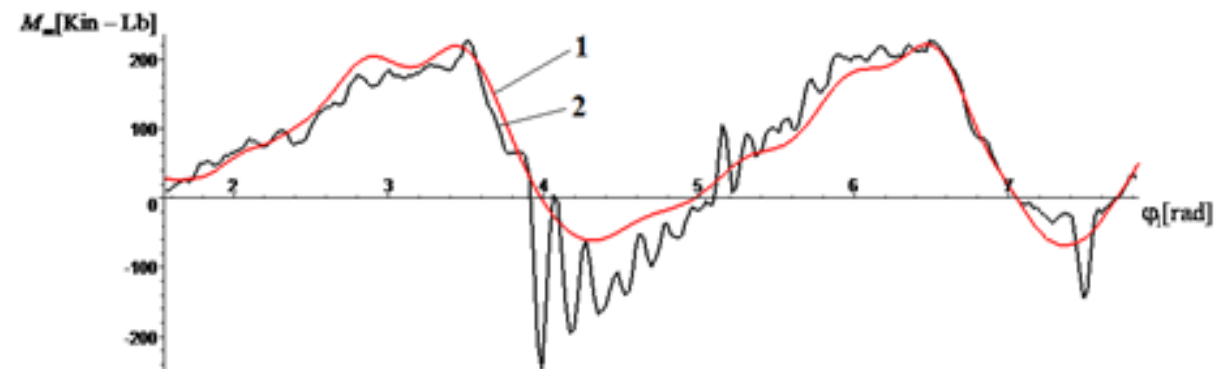

Fig. 13. The variation of the motor moment at the crankshaft during the stroke 85 (simulation -curve 1; experimental - curve 2)

In figures $11 \div 13$ the curve 1 represents the variation during a cinematic cycle beginning with the crank angle $\varphi_{1 d}$ of the motor moment $M_{m}$ at the crankshaft expressed in a polynomial form and the curves 2 corresponds to the variation of its measured values for the strokes 70,80 and 85 respectively.

Figures $11 \div 13$ highlight a good accordance between the values of the motor moment at the crankshaft obtained when it is expressed in the polynomial form and its measured values

\section{Conclusions}

In this paper were presented some results concerning the use of the polynomial functions in the operation analysis of the mechanism of the conventional pumping units. The program Total Well Management has been used for processing the experimental records and the simulations have been performed with a computer program developed by the author using Maple programming environment. After the simulations performed in the case of a C-640D-305120 pumping unit it has been established the variation on a cinematic cycle of the motor moment at the crankshaft in a polynomial form after having previously obtained the polynomial functions corresponding to the variation on a cinematic cycle of the force at the polished rod and of the angular speed of the rocker. The simulation results highlighted a good accordance between the values of the motor moment at the crankshaft obtained when it is expressed in the polynomial form and its measured values.

\section{References}

1.GIBBS, S G., Predicting the behavior of sucker-rod pumping systems, Journal of Petroleum Technology, 1963 (July), p. 769-778

2.GIBBS, S G., Computing gearbox torque and motor loading for beam pumping units with consideration of inertia effects, Journal of Petroleum Technology, 1975 (September), p. 1153-1159

3.POPOVICl, A., Equipment for the exploitation of oil wells (in Romanian), Technical Publishing House, Bucharest, 1989

4.BADOIU, D., TOMA, G., Research concerning the identification of some parameters of a sucker rod pumping unit, Rev. Chim. (Bucharest), 68, no. 10, 2017, p. 2289-2292
5.BADOIU, D., TOMA, G., Research concerning the kinetostatic analysis of the mechanism of the conventional sucker rod pumping units, Rev. Chim. (Bucharest), 69, no. 7, 2018, p. 1855

6.BADOIU, D., TOMA, G., Research concerning the correlations between some experimental results in the case of a sucker rod pumping installation, Rev. Chim. (Bucharest), 69, no. 11, 2018, p. 3060

7.BADOIU, D., TOMA, G., Research concerning the predictive evaluation of the motor moment at the crankshaft of the conventional sucker rod pumping units, Rev. Chim. (Bucharest), 70, no. 2, 2019, p. 378

8.TOMA, G., BADOIU, D., Research concerning the influence of some constructive errors on the dynamics of a pumping unit, PetroleumGas University of Ploiesti Bulletin, Technical Series, Vol. 63, no. 4, 2011, p. 27-30

9.BADOIU, D., TOMA, G., On a dynamic optimisation problem of the quadrilateral mechanism, Journal of the Balkan Tribological Association, Vol. 22, no. 1, 2016, p. 250-260

10.TOMA, G., BADOIU, D., On the cinematic analysis of a mechanism of fourth class, Petroleum-Gas University of Ploiesti Bulletin, Technical Series, Vol. 64, no. 1, 2012, p. 69-72

11.TOMA, G., BADOIU, Research Concerning the Calculus of the Equilibrium Moment in the Case of a Plane Mechanism Using the Dynamic Model, Petroleum-Gas University of Ploiesti Bulletin, Technical Series, Vol. 67, no. 2, 2015, p. 93-98

12.SHABANA, A.A., Dynamics of multibody systems, Cambridge University Press, 2005

13.SHIGLEY, J.E., UICKER JR., J.J., Theory of machines and mechanisms, McGraw-Hill, 1981

14.BADOIU, D., Dynamic analysis of mechanisms and machines (in Romanian), Didactical and Pedagogical Publishing House, Bucharest, 2003

15.MONAGAN, M.B., GEDDES, K.O., HEAL, K.M., LABAHN, G., VORKOETTER, S.M., MCCARRON, J ., DEMARCO, P., Maple Introductory Programming Guide, Maplesoft, a division of Waterloo Maple Inc., 2005

16.*** Total Well Management Help Manual, Echometer Company, Texas

17.*** Conventional Crank Balanced Pumping Units, Lufkin Oilfield Products Group, Houston, Texas

18.DODESCU, G., TOMA, M., Numerical calculus methods (in Romanian), Didactical and Pedagogical Publishing House, Bucharest, 1976

$\overline{\text { Manuscript received: } 19.06 .2018}$ 